\title{
Práticas Sustentáveis no contexto turístico: Estudo da Comunidade em Jenipabu (RN)
}

\section{Sustainable Practices in the Touristic Context: Community Study in Jenipabu (RN, Brazil)}

Margareth Ribeiro, Silvânia Cunha, Camila Targino, Amanda Almeida Gomes Dantas, Sueli Aparecida Moreira

\begin{abstract}
RESUMO: O presente estudo teve como objetivo apreender as percepções da comunidade de Jenipabu (termo Tupi) sobre adoção de práticas sustentáveis no contexto turístico. Realizou-se estudo da comunidade com abordagem qualitativa, cujos dados foram obtidos por meio de entrevistas durante rotina dos residentes. De acordo com Meksenas (2002), o estudo da comunidade procura observar e compreender o modo de vida das pessoas da comunidade. Os resultados mostraram que a atividade turística se encontra em declínio. A comunidade relatou a falta de investimento do Poder Público. Todavia, a comunidade reconheceu a importância dos atrativos naturais locais para o desenvolvimento do turismo. A comunidade demonstrou conhecimento sobre impactos do turismo no meio ambiente/sustentabilidade e a respeito do cuidado ideal com os resíduos sólidos (lixo e óleo de cozinha utilizado). Concluiu-se que o turismo ecológico de base comunitária poderá ser uma opção de desenvolvimento econômico para a comunidade.
\end{abstract}

PALAVRAS CHAVE: Ecossistema Dunar; Turismo Sustentável; Turismo de Base Comunitária; Estudo da Comunidade.

ABSTRACT: The present study aimed to apprehend the perceptions of the Jenipabu (Tupi term) community regarding the adoption of sustainable practices in the tourist context. A community study was carried out with a qualitative approach, whose data were obtained through interviews during the residents' routine. According to Meksenas (2002), the study of the community seeks to observe and understand the way of life of people in the community. The results showed that tourism activity is in decline. The community reported the lack of investment by the government. However, the community recognized the importance of local natural attractions for the development of tourism. The community demonstrated knowledge about tourism impacts on the environment / sustainability and about the ideal care with solid waste (garbage and used cooking oil). It was concluded that community-based ecological tourism could be an economic development option for the community.

KEYWORDS: Dune Ecosystem; Sustainable Tourism; Community-Based Tourism; Community Study. 


\section{Introdução}

O turismo é uma atividade multidimensional que representa uma das principais alternativas para promover o desenvolvimento regional, gerando oportunidades e soluções para combater a desigualdade social, envolvendo, portanto, aspectos econômicos, políticos e acadêmicos em busca do seu desenvolvimento de modo sustentável (TOMAZZONI, 2009).

A sustentabilidade é um termo utilizado no planejamento do turismo por relaciona-se à preservação do meio ambiente. Nesse sentido, há métodos eficazes aplicados no uso de recursos naturais escassos de maneira adequada em um determinado ponto turístico, bem como a preservação da identidade local para que possam continuar sendo proveitosos à comunidade e gerações, aos visitantes e às gerações futuras (BRUNDTLAND REPORT, 1987; SWARBROOK, 2000).

Para Beni (2000), o turismo sustentável é capaz de preservar e utilizar os recursos ambientais e coopera de forma consciente com o processo do turismo. $O$ autor aponta o planejamento estratégico e integrado do desenvolvimento sustentável do turismo como uma forma de dinamizar o desenvolvimento econômico e social de uma região. O turismo sustentável, contemplando um plano estratégico de ação, poderá funcionar e contribuir com benefícios para a comunidade local.

O desenvolvimento sustentável do turismo depende da utilização dos recursos naturais de forma cautelosa, garantindo o equilíbrio da biodiversidade. Desse modo, é importante apresentar o termo Ecoturismo que surgiu com a finalidade de utilizar os princípios ambientais, como meio de solucionar graves problemas ambientais e contribuir com mudanças que possam reverter a destruição provocada pelo homem (MACHADO, 2005).

A comunidade pode utilizar os recursos naturais através das modalidades que envolvem a natureza como o turismo de aventura, turismo ecológico, turismo pedagógico, entre outras. Pode ser interpretado como uma estratégia que fortalece e melhora a economia, acentua a necessidade de preservação ambiental e cultural (para que as gerações futuras também desfrutem desses bens) e garante a melhoria da qualidade de vida da comunidade (BENI, 2000).

Considerando a valorização da identidade cultural regional/local através da participação da comunidade no planejamento estratégico do turismo, realizou-se o presente estudo para apreender as percepções de representantes da comunidade de Jenipabu/RN, a respeito da adoção de práticas sustentáveis no contexto turístico.

\section{Referencial Teórico}

O turismo é uma área de estudo relativamente recente e, aos poucos, adquire maior relevância acadêmica por ser uma atividade capaz de provocar transformações benéficas na sociedade. O planejamento turístico consiste numa estratégia de desenvolvimento regional, reconhecimento e valorização da cultura, oportunidade de emprego, geração de renda e inclusão social. Dessa forma, Cooper (2007, p.40) afirma que o turismo é: 
Uma atividade importante e suficiente em termos econômicos, e o impacto que produz sobre as economias, os ambientes e as sociedades é bastante significativo [..] É uma atividade multidimensional, multifacetada, que influencia muitas vidas e muitas atividades econômicas diferentes (COOPER, 2007, p. 40).

Em relação ao turismo, Dias (2008, p.10) aconselha considerar que:

Ao afetar direta e indiretamente diversos setores da economia, tornase poderoso instrumento de desenvolvimento, abrindo a possibilidade de um número significativo de empregos diretos e indiretos (dos mais qualificados aos menos) e um sem-número de postos de trabalho. O turismo pode ser considerado como umas das poucas alternativas à destruição do emprego tradicional devido ás mudanças tecnológicas e a globalização, junto com a redução de jornada de trabalho (DIAS, 2008, p. 10).

O turismo é uma área diversificada e destaca-se no âmbito econômico por impulsionar o desenvolvimento de determinada região. Nessa perspectiva, o turismo depende de alguns atores para ser ampliado de maneira eficaz, em que beneficie todos os envolvidos. Assim, segundo Ignarra (2013, p.13), esse fenômeno permeia quatro componentes com perspectivas diversas:

O turista, que busca diversas experiências e satisfações espirituais e físicas; os prestadores de serviços, que encaram o turismo como um modo de obter lucros financeiros; o governo, que considera um fator de riqueza para a região sob sua jurisdição; a comunidade do destino turístico, que vê a atividade como geradora de empregos e promotora de intercâmbio cultural (IGNARRA, 2013, p.13).

O turismo proporciona mudanças significativas na sociedade e o turista é o "ator principal" que irá desfrutar dos produtos e serviços prestados através da busca de novas experiências (IGNARRA, 2013). Segundo Mielke (2009), o turismo pode ser considerado um serviço pessoal, pois não há substituição do homem por máquinas produtivas. Percebe-se então, que o homem tem um papel relevante na atividade turística, como por exemplo, a capacidade de amenizar os problemas da sociedade moderna. Por isso o conhecimento, qualificação e capacitação são essenciais para planejar e manter o turismo de forma sustentável.

A vulnerabilidade de um atrativo ou local turístico depende da fragilidade dos ecossistemas que compõem o meio e, para preservar sua integridade, é preciso delimitar a capacidade de carga que este pode suportar sem comprometer as características que originaram sua atratividade (RUSCHMANN, 2016).

Nos países em desenvolvimento, dentre os quais se inclui o Brasil, a ênfase na proteção dos recursos naturais e valorização das comunidades receptoras (geralmente pobres) é especialmente importante, devido aos efeitos danosos do turismo de massa, que ignora e literalmente invade os recursos naturais e alija as comunidades locais do processo produtivo, além de comprometer sua herança 
cultural - muitas vezes única e de origens remotas. Além disso, entende-se que o ecoturismo somente terá efeitos benéficos e conservacionistas nos meios visitados se incluir a educação ambiental dos visitantes, transformando o turista em protetor do meio visitado (RUSCHMANN, 2000).

\title{
Turismo Sustentável
}

Segundo Dias (2008), o conceito sustentabilidade surgiu com intuito de harmonizar as diversas dimensões de desenvolvimento que até então privilegiava quase que exclusivamente o econômico. É um termo que traz uma visão de futuro, estabelecendo metas para que o crescimento atual não comprometa o meio ambiente das gerações futuras. Nesse sentido, Philippi e Ruschmann (2010, p.73) apontam:

\begin{abstract}
A ideia de sustentabilidade aliada a desenvolvimento foi se constituindo ao longo da década de 1980, e se materializou no relatório Brundtland, denominado Nosso Futuro Comum (World Comission Environmental and Development, 1987), no qual aparece a definição mais oficial de desenvolvimento sustentável (PHILIPPI e RUSCHMANN, 2010, p. 73).
\end{abstract}

Permitir o desenvolvimento sustentável é preservar e conservar os recursos naturais, estabelecendo metas que possibilitem minimizar os impactos negativos provocados pela falta de planejamento político-governamental e diálogo com a sociedade. Philippi e Ruschmann (2010) enfatizam que:

No contexto de desenvolvimento sustentável deve-se lembrar de que a questão da infraestrutura e, em seu bojo, da energia envolve também o problema da equidade, englobando o combate à pobreza e o atendimento as necessidades básicas de alimentação, saúde e moradia. Esses aspectos apresentam grande importância para os países em desenvolvimento, principalmente no que se refere às pequenas comunidades em regiões isoladas para as quais o turismo pode ser um importante vetor na construção do desenvolvimento sustentável (PHILIPPI; RUSCHMANN, 2010, p.635).

A Conferência das Nações Unidas para o meio ambiente, que ocorreu em 1972 no Rio de Janeiro, tinha a sustentabilidade como um de seus pontos principais. Todavia, o turismo não se encontrava na ordem do dia das discussões e, portanto, nenhuma expressão ou referência resultou nos documentos do Encontro.

O conceito de turismo sustentável só foi consolidado através de vários processos e discussões que envolveram vários estudiosos, a ONU e principalmente a OMT, pautando o turismo sustentável como objeto de pesquisa desde sua criação (DIAS, 2008). Alcançar o turismo sustentável é um processo contínuo e requer monitoramento constante dos impactos, a introdução de medidas preventivas e/ou corretivas sempre que necessárias (BENI, 2012). 
Magalhães (2002, p.89) afirma que "a ideologia do turismo sustentável traz na sua base a preocupação com a conservação do meio físico e das formas de organização das comunidades receptoras nas fases de planejamento".

Com o avanço do incentivo ao turismo sustentável, a segmentação turística proporcionou campos que dificilmente seriam visitados. Assim, o turismo em localidades monitoradas por órgãos Federais, Estaduais e Municipais, conhecidos comumente como Áreas de Proteção Ambiental (APA) ou Unidades de Conservação (UC), foi capaz de gerar uma renda extra para manter o ambiente preservado e principalmente conscientizar através do turismo.

Desse modo, estabelecendo os critérios ambientais na atividade turística, o ecoturismo surgiu como o meio de solucionar graves problemas ambientais e contribuir com soluções que possam reverter a destruição provocada pelo homem. É capaz de estabelecer uma nova relação do homem com o meio em que atua (MACHADO, 2005).

\section{Ecoturismo}

O Ecoturismo ou turismo alternativo é o diferencial para os turistas que procuram sair da paisagem urbana, através de experiências na natureza que satisfaçam suas expectativas e proporcionem conhecimento através do lazer. Segundo Brunelli (2003), o avanço tecnológico coincidiu com a redução de paisagens naturais, motivando a busca pelo contato com a natureza, reconhecendo, então, o seu valor.

O ecoturismo permite ao turista a experiência de desfrutar do contato com a natureza para o seu bem-estar sem exceder aos valores da comunidade local. Brunelli $(2003$, p.6) enfatiza que são necessárias quatro condições básicas para uma atividade ser considerada como ecoturismo:

Respeito às comunidades locais, envolvimento econômico efetivo das comunidades locais, respeito às condições naturais e conservação do meio ambiente e interação educacional - garantia de que o turista incorpore para a sua vida a preservação da natureza e dos patrimônios histórico, cultural e étnico (BRUNELLI, 2003, p. 6).

Os autores Mendonça e Neiman (2005) ampliam o conceito de ecoturismo ao considerá-lo como uma atividade que instrumentaliza a aproximação entre o ser humano e o meio ambiente selvagem, principalmente em Unidades de Conservação. Os autores sugerem que sejam incorporados alguns pressupostos, como o questionamento de valores, a aprendizagem através de experiências e a busca de reformulações para aspectos indesejáveis da vida cotidiana (MENDONÇA; NEIMAN, 2005, p.18).

O ecoturismo é uma estratégia de desenvolvimento regional que privilegia a identidade cultural local. De acordo com Amorim (2003) a estreita relação entre ecoturismo e a comunidade permite, dentre outras vantagens, a valorização da prestação de serviço sem intermediação e o sentimento de pertencimento da hospitalidade local, minimizando os efeitos do pós-negócio decorrentes de atividades meramente lucrativas ou econômicas. 
Dessa forma, o ecoturismo pode ser inserido em Unidades de Conservação (UC) pelo motivo de transmitir conhecimento e preservar o meio ambiente. Machado (2005) esclarece, em relação a essa forma de turismo, a diferença entre os termos de conservação e preservação:

No ecoturismo, utilizamos o termo conservação para as áreas que possibilitem a visitação pública e a prática de determinadas atividades compatíveis com a manutenção dos espaços. Já a preservação diz a respeito às áreas intangíveis para o visitante, nas quais nenhuma possibilidade de visitação é oferecida (MACHADO 2005, p. 25).

O ecoturismo quando planejado e organizado, torna-se uma fonte de benefícios econômicos para os Estados, empresas privadas e comunidades locais. Podendo ser um instrumento eficaz para a conservação dos recursos naturais e culturais (BRUNELLI, 2003).

\section{Turismo Comunitário}

O turismo comunitário é uma modalidade que colabora com a valorização da cultura local e com o provimento da renda dos residentes. A valorização da cultura é essencial para a iniciativa desse segmento na comunidade, mantendo a identidade intacta com a manutenção de costumes e tradições antigas. Desse modo, o estilo de vida simples e digno dos anfitriões é evidenciado.

A preservação da identidade local tem auxiliado para que os moradores locais se expressem cada vez mais sem o constrangimento da crítica e da rejeição pela clientela convencional. Amorim (2003) afirma que:

Quando os negócios são explorados pela população local, a renda gerada fomenta a própria região. Pode-se perceber que, em muitos locais onde os negócios são explorados por pessoas que não são da própria comunidade, boa parte da renda é reinvestida em grandes centros, causando conflitos sociais ao longo do tempo (AMORIM, 2003, p. 72).

Reitera-se a importância das iniciativas locais, regionais, com diagnósticos na comunidade, investimentos na infraestrutura, qualificando para a hospitalidade. A infraestrutura melhora significativamente a imagem da comunidade, obtendo deste modo, benefícios para ambos: residentes e turistas. Nesse contexto, Cooper (2007) afirma que:

Quando se desenvolve o turismo em um destino, a infraestrutura local é frequentemente aprimorada para atender as necessidades desse desenvolvimento. A comunidade local pode concluir que sua qualidade de vida melhorou significativamente ao poder desfrutar dessa infraestrutura mais qualificada (COOPER, 2007, p. 256). 
Esse aperfeiçoamento na infraestrutura pode repercutir na melhoria das condições de saúde obtidas pela recuperação do suprimento de água e saneamento básico. Instalações esportivas, equipamentos de lazer, construção de aeroportos e acesso a voos regulares, restaurantes e uma diversidade de alimentos e bebidas têm contribuindo com aumento da oferta e demanda no destino turístico. Portanto, envolve a responsabilidade dos vários participantes, inclusive setores públicos e privados, turistas e população local (COOPER, 2007).

\section{Método}

Trata-se de uma pesquisa de natureza qualitativa, cuja abordagem se deu através do estudo da comunidade de Jenipabu, que está localizada no município de Extremoz, estado do Rio Grande do Norte.

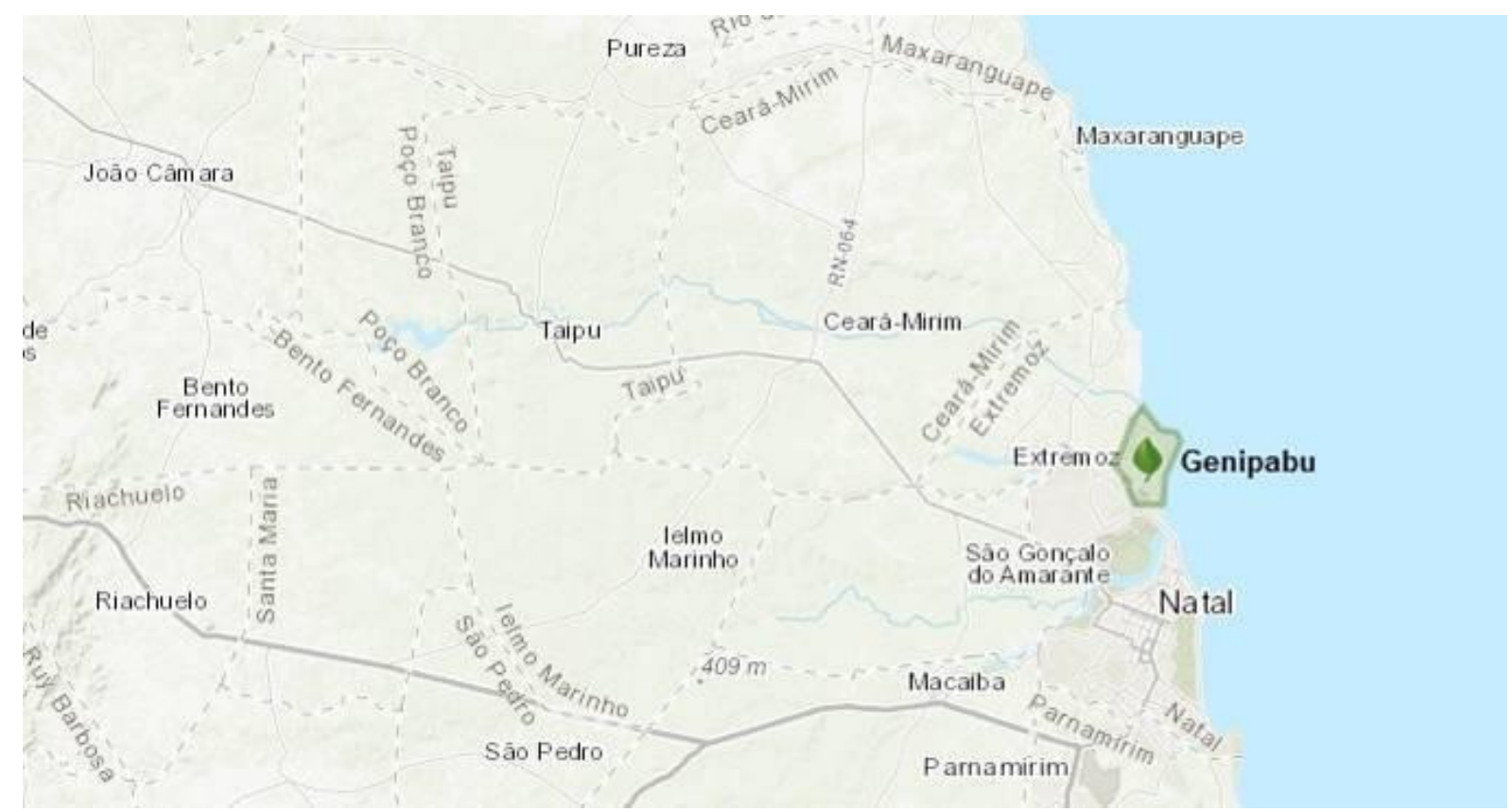

Figura 1: Mapa de localização de Jenipabu/RN. Fonte: uc.socioambiental.org/arp/2013 Figure 1: Jenipabu/RN location map. Source: uc.socioambiental.org/arp/2013

De acordo com Meksenas (2002), o estudo da comunidade procura observar e compreender o modo de vida das pessoas, interpretando suas crenças, religiões, suas formas de educação e seus hábitos. Como também, a visão do mundo moderno que possuem, avaliando o efeito dessa modernidade em suas vidas. $O$ autor ainda aponta que:

Os estudos de comunidades não são adequados ao exame de qualquer realidade social. $O$ que está em jogo nessa modalidade de pesquisa é o interesse de capturar a tensão existente entre o moderno e o tradicional dentro de contextos empíricos. Trata-se também de uma modalidade de pesquisa que requer a presença e a inserção do investigador na realidade em foco: participar, por um período determinado, da vida da comunidade, observar sua rotina e as atividades que a "quebram", conversar com as pessoas, buscar o 
entendimento e o significado de suas ações [...]. Enfim o pesquisador deve "mergulhar" no espaço de criação da pesquisa (MEKSENAS, 2002, p.114).

Foi definida uma amostragem não probabilística, definida por acessibilidade aos sujeitos, sendo que a comunidade não alcança duas mil pessoas. Contudo, o comercio à beira mar concentra meia dúzia de restaurantes e bares, a mesma quantidade de barracas de vendas de alimentos e bebidas, algumas lojas de artesanatos e alguns estabelecimentos de passeios turísticos.

Portanto, foram arrolados 28 representantes provenientes da maioria dos estabelecimentos. A faixa etária era de jovens e idosos, cuja atividade envolvia o comercio de artesanatos e ou se ocupavam de barracas para venda de petiscos e bebidas na praia. Todos estavam relacionados diretamente ao turismo local. Foi analisado o cotidiano deles para observar a adoção de práticas sustentáveis em atividades turísticas no contexto da comunidade.

\section{Abordagem durante a coleta de dados}

Os dados foram obtidos através de entrevistas e depoimentos dos residentes e, durante a coleta, foram utilizados formulários sobre o perfil sociodemográfico dos entrevistados, para obter informações de faixa etária, gênero, grau de escolaridade e proveniência dos sujeitos. Além disso, o instrumento abordava questões relacionadas com a atividade turística existente na comunidade (atrativos e serviços) e as práticas sustentáveis (descarte de resíduos como o óleo e lixo, o cuidado sustentável dos atrativos naturais).

A coleta de dados foi organizada em 3 (três) etapas que abrangeram: o perfil do entrevistado, o fenômeno turístico local e as práticas sustentáveis. Para analisar e interpretar os dados obtidos foi utilizada a proposta de Deslandes (2016), cuja análise de conteúdo compreendeu os procedimentos de: inferência, descrição, categorização e interpretação.

Elaborou-se um corpus tópico, para registro dos dados, depoimentos dos entrevistados, facilitando a interpretação e a organização das categorias. Segundo Bauer e Aarts (2004), esse recurso pode ser planejado para um fim estritamente definido de pesquisa; ele pode tornar-se um recurso geral de investigação para análise durante pesquisa social com base em texto ou entrevistas. Em relação aos aspectos éticos, respeitou-se a Resolução CNS/MS 466/2012, assegurando o sigilo do depoente através do uso de nomes fictícios. Também se utilizou o termo de consentimento livre e esclarecido (TCLE) aos entrevistados antes da coleta.

\section{Resultados e discussão}

\section{Perfil sócio demográfico dos entrevistados}

Foram incluídos no estudo 28 participantes. A maioria das pessoas entrevistadas era do sexo feminino $(64,3 \%)$, encontravam-se na faixa etária acima de 30 anos $(78,6 \%)$, eram solteiras $(46,7 \%)$, e possuíam ensino médio completo (42,9\%). No que diz respeito à origem, $64,3 \%$ dos participantes eram de Jenipabu, conforme os dados dispostos na Tabela 1, a seguir: 
Tabela 1: Análise descritiva do perfil sociodemográfico dos entrevistados da comunidade de Jenipabu. Natal, Rio Grande do Norte, Brasil, 2016. $n=28$.

Table 1: Descriptive analysis of the socio-demographic profile of respondents from the Jenipabu community. Natal, Rio Grande do Norte, Brazil, 2016. $n=28$.

\begin{tabular}{lll}
\hline Variável & $\mathbf{N}$ & $\%$ \\
\hline Sexo & & \\
Masculino & 10 & 37,7 \\
Feminino & 18 & 64,3 \\
Faixa Etária & & \\
Até 30 anos & 6 & 21,4 \\
Acima de 30 anos & 22 & 78,6 \\
Escolaridade & & \\
Ens. Fundamental Incompleto & 10 & 35,7 \\
Ens. Médio Completo & 12 & 42,9 \\
Ens. Superior Completo/Incompleto & 3 & 10,7 \\
Origem & & \\
Jenipabu & 18 & 64,3 \\
Natal & 6 & 21,4 \\
Outros & 4 & 14,3 \\
Total & $\mathbf{2 8}$ & $\mathbf{1 0 0 , 0}$ \\
\hline
\end{tabular}

Fonte: Pesquisa DETUR/UFRN, 2016.

Source: Research DETUR/UFRN, 2016.

\section{Percepção sobre a atividade turística local \\ O turismo de Jenipabu}

Para melhor compreensão das respostas sobre a caracterização da atividade turística de Jenipabu, os dados foram organizados em categorias a partir das opiniões mais frequentes e relevantes.

Durante a análise temática sobre a atividade turística junto à comunidade constatou-se que as respostas mais relevantes (27 entrevistados) apontaram que a atividade turística se encontra em estado crítico. No decorrer dos depoimentos as frases mais utilizadas para caracterizá-la foram "está muito fraca" e "está péssima". Outros 5 (cinco) entrevistados complementaram suas respostas enfatizando que o principal motivo para a queda e desvalorização do turismo foi a falta de infraestrutura e investimento:

\footnotetext{
Precisando melhorar a infraestrutura hoteleira e de restaurantes, 0 movimento está fraco (Antônio, 56);

Caiu bastante devido à falta de infraestrutura (Henrique, 40);

Saturada, abandonada precisando de reparos (Isabel, 25);

Fraca pela falta de estrutura e investimento (Carlos, 34);

Porcaria, não tem estrutura para receber os turistas (Ana, 48).
}

A crise no Brasil como motivo para a desvalorização da atividade turística, também foi apontada pelos residentes nas seguintes frases: "está muito fraca em virtude da crise no Brasil" (Izabel, 75 anos) e "Não está muito boa, como era antigamente devido à crise do Brasil" (Paulo, 74 anos). $\mathrm{Na}$ análise a respeito da atividade turista, apenas um entrevistado relatou que a mesma estava boa. 


\section{Influência dos atrativos naturais na opinião de turistas em Jenipabu/RN}

Os atrativos naturais de Jenipabu são compostos pelas dunas móveis e dunas fixas, onde acontecem os passeios de buggy e dromedários; a lagoa que também se encontra dentro de uma Área de Proteção Ambiental (APA); a praia, onde acontece o passeio de jangada e cavalo. Há também lojas de artesanatos, barracas e restaurantes e o rio em que se encontram as balsas para viabilizar o acesso a outras praias do litoral norte.

Ao avaliar a influência dos atrativos naturais na localidade, observou-se uma relevância nas respostas de total concordância em que 17 (dezessete) entrevistados acreditam que tais atrativos influenciam na visita dos turistas. Com as respostas de total concordância, 2 (dois) entrevistados complementaram relatando "que se não fossem os atrativos naturais não haveria motivos de conhecer Jenipabu". Outros dois argumentos ainda notavam o encantamento dos turistas pelas belezas naturais, sendo este o principal motivo de visita:

Com certeza, se não fosse os atrativos naturais, Jenipabu não seria visitado (Gisele, 27);

Sim, se não fossem eles não viriam ninguém para cá (José, 58 );

Sim, são os principais motivos de visita dos turistas (Marta, 42);

Sim, os turistas se encantam pelas belezas naturais (Ana, 75).

Cinco dos relatos priorizaram apenas a praia e as dunas de Jenipabu, ressaltando que seriam esses os principais motivos da visita dos turistas. Pelo motivo da maior parte do comercio e serviços prestados pela comunidade estarem presentes nesse entorno: passeio de buggy, dromedário, jangada, as lojas de artesanatos, as barracas de praia, restaurantes e bares:

As dunas são o principal atrativo dos turistas (Luiz, 40);

Sim principalmente as dunas (Beatriz, 25);

Apenas as dunas e a praia (Rosa, 53);

A praia e as dunas, a lagoa e o rio (Paula, 50; Nilda, 48).

Embora esteja localizada dentro de uma APA, o acesso à lagoa pode ser permitido mantendo-se o controle de visitação e monitorando a capacidade de carga conforme proposta de Ruschmann (2016). Indo além, a capacidade de carga ecológica refere-se ao número de visitantes simultâneos e ao número de frequências que pode absorver uma área natural, sem que se altere o equilíbrio do ecossistema (BOULLÓN, 2003). Desta maneira, a comunidade instrumentaliza a atividade turística, de lazer e apreciação da paisagem da lagoa.

Percebe-se então, a falta de divulgação por parte dos representantes da comunidade, sendo até mesmo contraditório ao plano de manejo criado desde 2009, pela própria entidade responsável. Como é observado:

A Área de Proteção Ambiental Jenipabu - APAJ possui o seu Plano de Manejo desde 2009 onde é um dos mais importantes documentos de uma Unidade de Conservação, pois define estratégias de atuação, diversos programas a serem implementados, como por 
exemplo, divulgação e marketing da Unidade, Fiscalização e Educação Ambiental (SECOM/IDEMA, 2016, p.1).

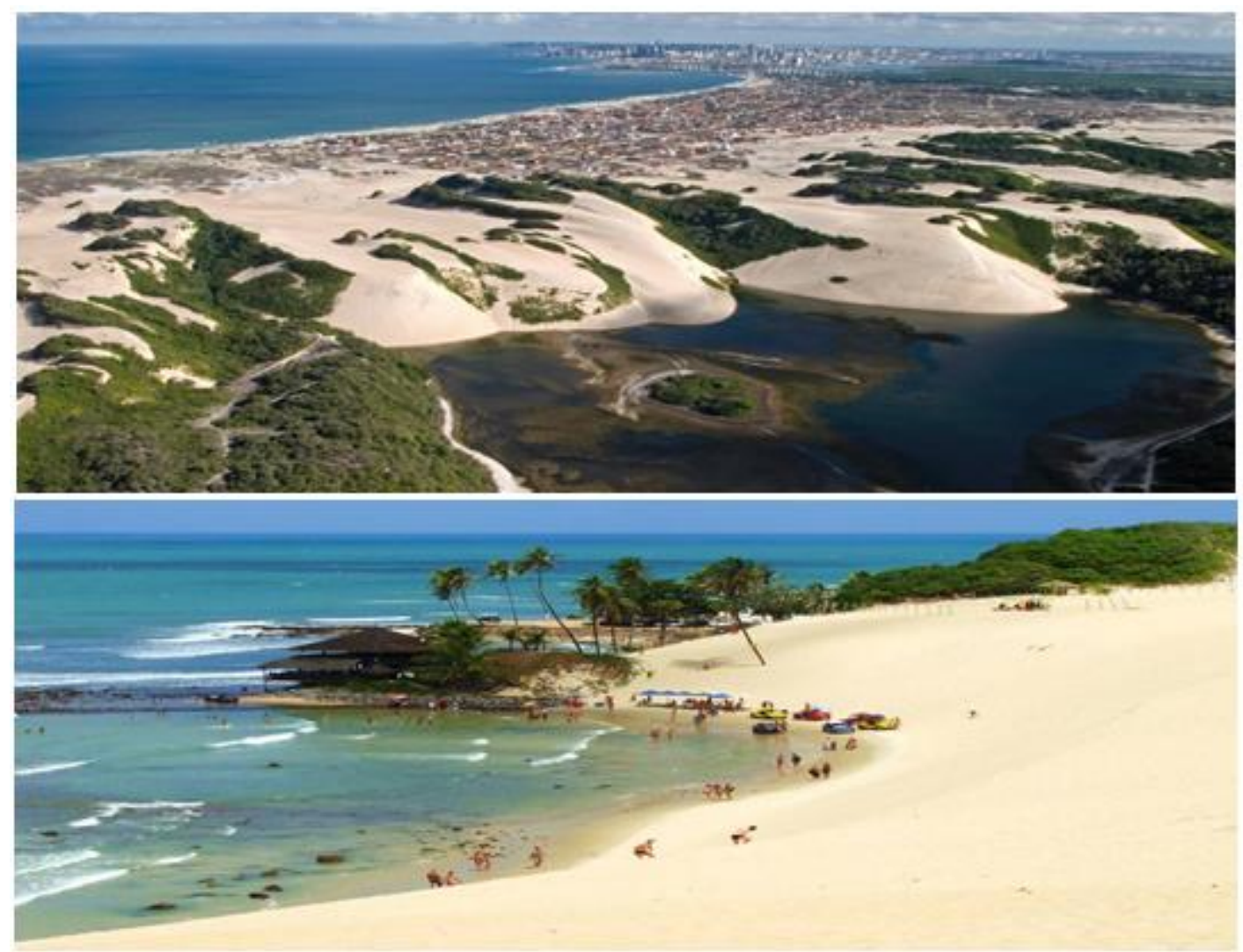

Figura 2: Paisagens da Lagoa e Praia de Jenipabu/Extremoz/RN, 2012.

Figure 2: Landscapes of the Lagoon and Jenipabu Beach/Extremoz/RN, 2012.

Fonte: SOARES, Canindé, 2012.

Source: SOARES, Canindé, 2012.

\section{Opinião da comunidade sobre o passeio de buggy e dromedário em Jenipabu/RN}

Ao analisar as opiniões dos residentes da comunidade a respeito do passeio de buggy e dromedário constatou-se maior evidência de relatos positivos. Notou-se com ênfase na importância dos passeios para o turismo local, sendo esses os responsáveis pela frequência de turistas. Assim, os passeios contribuem com a oferta de empregos para os residentes e o encantamento dos turistas ao desfrutálos, pois são serviços diferenciados em relação a outros destinos turísticos:

O passeio de buggy nas dunas é a principal fonte de renda e o dromedário é o diferencial nas dunas (Gizele, 27);

São bons, se eles não existissem os turistas não tinham motivos para visitar Jenipabu (Luiz, 40);

Atrações fundamentais para o turismo (Gileno, 52);

Muito bom, se não fossem eles o turismo já tinha acabado (Neuza, 40). 
Apenas 3 (três) entrevistados mostraram ter opiniões diferentes em relação aos passeios. Nesses relatos a justificativa foi em relação aos preços altos e o uso ecologicamente incorreto dos passeios. Como é possível observar:

Não é correto ecologicamente, mas se tirar acaba o turismo. Vai continuar por ser bastante procurado (Izabel, 75);

Interessante, mas muito caro. Se diminuir o valor haverá o aumento no fluxo de turistas (Iris, 26);

É muito bom, mas é caro. Espero que melhore (Nilda, 40).

Os preços altos dos serviços dificultam a utilização por pessoas de baixo poder aquisitivo. Desse modo, é necessário que os serviços prestados na localidade se tornem mais acessíveis, classificando os passeios em níveis de demanda e com trechos alternativos.

Foi abordado o seguinte questionamento: se há perspectiva futura de continuidade dos passeios. Nas respostas obtidas houve opiniões de natureza positiva, negativa e incerta. Todavia, foi relatada a importância de investimento para que o passeio possa continuar. Os argumentos positivos enfatizaram o uso correto do meio ambiente nos serviços prestados pelos passeios, opiniões nas quais privilegiam como idealizadores do turismo local:

Vão continuar por ser bastante procurado (Izabel, 75);

Vão continuar por desenvolver um trabalho muito bonito (Marta, 68);

Por serem sustentáveis pode continuar (Gileno, 52);

Vão continuar, por serem sustentáveis (Islane, 40).

Nos depoimentos negativos, 4 (quatro) entrevistados opinaram que os passeios acabarão por causa da carência na infraestrutura local, falta de divulgação e o uso excessivo das dunas. Outros entrevistados enfatizaram que tais passeios continuarão, no entanto, desvalorizados, devido à concorrência com destinos melhores e a desorganização nos serviços prestados dos passeios:

[...] Vão acabar pela falta de divulgação e investimento (Milena, 34);

[...] Vão continuar, mas não como era antes haverá uma queda devido à desorganização (Ana, 23);

[...] São os principais atrativos. Haverá uma queda devido à concorrência com destinos melhores (Rian, 34);

[...] Com o tempo vai acabar devido ao uso excessivo das dunas (Giane, 27).

Em relação aos depoimentos de incerteza, constatou-se que para os passeios continuarem dependiam de fatores como: investimentos, apoio político, trabalhos de conscientização ambiental e fiscalização do IDEMA. Desta forma, sendo implementadas essas ações os passeios continuariam fortalecendo o turismo local. Como é possível observar nos relatos a seguir:

[...] Se tiver um trabalho de conscientização ambiental do uso dos atrativos naturais deverá se manter (Willian, 56);

[...]Vai melhorar se houver investimento (Paulo, 48); 
[...]Se não houver uma maior fiscalização do IDEMA vai acabar (Flávio, 22);

[...] Se não respeitar o meio ambiente, se não houver um apoio político vai acabar (Neuza, 48).

Fica claro que os entrevistados têm conhecimento da importância de investimentos e apoio de órgãos governamentais no planejamento do turismo. Tal afirmação justifica-se diante da preocupação com o uso atual do meio natural e da infraestrutura onde ocorrem os passeios.

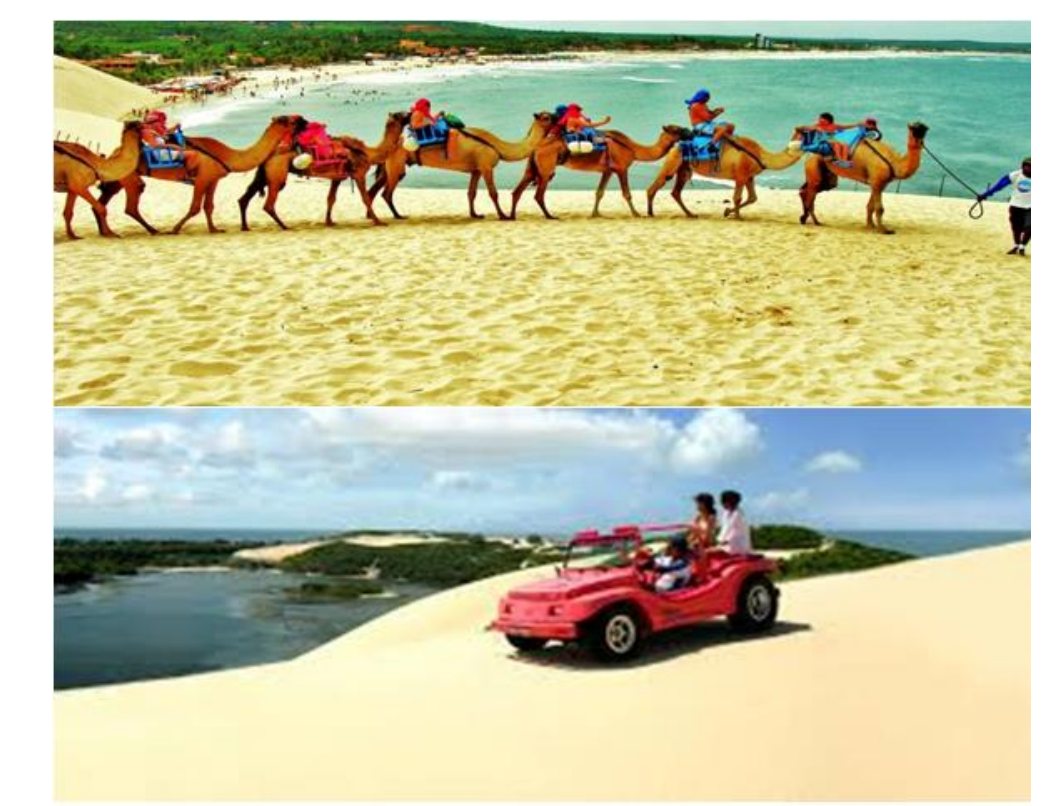

Figura 3: Passeios de Dromedário e de Buggy em Jenipabu/RN, 2019.

Figure 3: Dromedary and Buggy Tours in Jenipabu/RN, 2019.

Fonte: Site Praias de Natal, 2019.

Source: Natal Beaches website, 2019.

\section{Atrativos turísticos da comunidade de Jenipabu/RN para 0 desenvolvimento}

Ao analisar as opiniões dos entrevistados sobre o que poderia fazer parte do desenvolvimento do turismo, a questão revelou potencialidades que deveriam ser mais divulgadas por caracterizar a atividade turística existente na comunidade.

Nos relatos dos entrevistados, a lagoa e os passeios (de jangada, cavalo, charrete e jegue) foram os mais apontados, sendo esses os atrativos essenciais para o desenvolvimento do turismo e que não são divulgados em relação ao passeio de buggy e dromedário.

A lagoa foi o passeio mais relevante em que 12 (doze) entrevistados questionaram a desvalorização do atrativo por estar fechada para fins turísticos e principalmente para a comunidade. Segundo uma anfitriã era tradição no divertimento dos residentes: 
A lagoa que deveria reabri para o uso turístico (Renata, 56);

A lagoa de Jenipabu e as trilhas ecológicas (Willian, 56).

É relevante que a lagoa faça parte da atividade turística local, tendo em vista relatos anteriores dos entrevistados com queixa recorrente por ela estar fechada. Constatou-se, ainda, que a lagoa faz parte do desenvolvimento turístico. Desfrutar dos recursos naturais que estão dentro de uma Área de Proteção Ambiental de maneira consciente, divulgando sobre a importância deles para a sustentabilidade do local. Estratégia que vem sendo adotada em vários destinos turísticos que tiveram os recursos naturais ameaçados (AMORIM, 2003).

Com relação aos passeios de jangada (Figura 4), burro, jegue, cavalo, 10 (dez) entrevistados relataram a importância de valorizar esses serviços. Mesmo que seja caracterizado como trabalho informal, complementa a renda da comunidade.

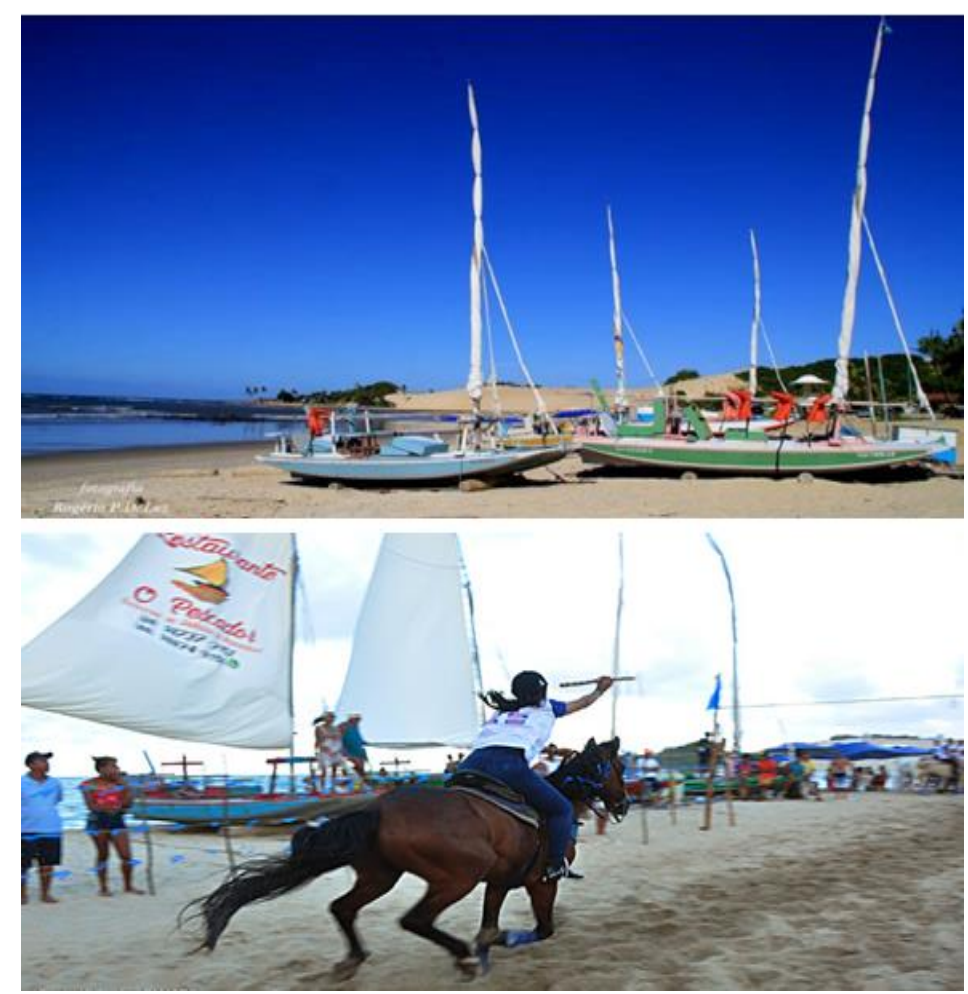

Figura 4: Passeio de jangada e Festa da Argolinha em Jenipabu/RN, 2019. Figure 4: Raft ride and Argolinha Party in Jenipabu/RN, 2019.

Fonte: SANTOS, Canindé, 2019.

Source: SANTOS, Canindé, 2019.

A cultura também foi alvo de valorização conforme relato dos entrevistados. $\mathrm{Na}$ atividade turística existente em Jenipabu, é ausente a divulgação das manifestações que acontecem na igreja (Festa do Padroeiro de Jenipabu - São Sebastião) e da cultura (Capoeira, Pastoril e Coco de Roda).

Em 3 (três) relatos de anfitriãs da comunidade foi identificada a demanda da participação da comunidade em resgatar a cultura, e que poderiam fazer parte do desenvolvimento do turismo na comunidade:

A festa do padroeiro deveria ser mais divulgada (Flávia, 70); 
A igreja, a cultura e a lagoa por ser tradição no divertimento das pessoas (Izabel, 75);

A cultura local deveria ser mais valorizada. Antigamente as pessoas apresentavam o pastoril, a dança do coco na praça em frente à igreja ultimamente não é mais visto (Carla, 68).

Em relação aos atrativos de Jenipabu, 2 (dois) entrevistados afirmaram que: "os atrativos existentes já são suficientes, pois são bastante divulgados" (Carlos, 30); "O que tem é suficiente para desenvolver o turismo" (Gabriel, 59). Apenas uma pessoa não soube responder à questão.

\section{Aspectos negativos do turismo segundo a comunidade de Jenipabu/RN}

$\mathrm{Na}$ análise dos fatores negativos, as respostas foram diversificadas, o que representa as inúmeras dificuldades que Jenipabu enfrenta com a precariedade da infraestrutura local e a carência no receptivo do destino.

A resposta mais recorrente foi a precariedade na infraestrutura local. Nesse sentido, 10 (dez) entrevistados argumentaram que a infraestrutura básica da comunidade é fundamental para o bem-estar local e desenvolvimento do turismo:
A falta de transporte e falta de infraestrutura (Miriam 40);
O posto de saúde que não abre nos finais de semana (Joelma, 68);
A falta de segurança e o desprovimento na educação das escolas (Paulo, 48);
A falta de organização nos estabelecimentos (Liana, 36).

A desorganização no receptivo do destino também é uma questão que preocupa os entrevistados, que veem o turismo decair em consequência dos impactos negativos e que não são solucionados pelos órgãos governamentais. Os principais motivos que prejudicam o receptivo de Jenipabu, de acordo com 9 (nove) entrevistados são: a abordagem e 0 atendimento negativo dos garçons e guias quando os turistas chegam à praia, os preços abusivos e a desorganização nos estabelecimentos:

A falta de infraestrutura, a abordagem negativa dos garçons e guias e os preços abusivos (Beatriz, 75);

À abordagem negativa dos garçons, exploração nos preços e falta de organização nos empreendimentos turísticos (Carol, 23);

Os preços exuberantes, as abordagens das pessoas que trabalham com o turismo, a falta de estrutura, falta de qualificação (Gizele 26);

Os preços abusivos, o mau atendimento dos garçons (Felipe, 58).

As opiniões dos entrevistados sobre essa questão somam-se aos relatos da questão anterior (percepção sobre o turismo de Jenipabu) e torna nítida a ineficácia dos órgãos governamentais diante do bem-estar da comunidade e no planejamento do turismo. 


\section{Benefícios do turismo para a comunidade de Jenipabu/RN}

Durante a análise dos dados obtidos e em atenção aos benefícios do turismo para a comunidade, pôde-se observar a relevância nas respostas que enfatizaram melhorias na infraestrutura. Assim, 13 (treze) entrevistados apontaram as reivindicações básicas da comunidade como: transporte, segurança e educação. Como também melhorias relacionadas com a orla marítima, investimentos nos setores de A\&B (alimentos e bebidas) e o entretenimento à noite. Como é possível observar a seguir:

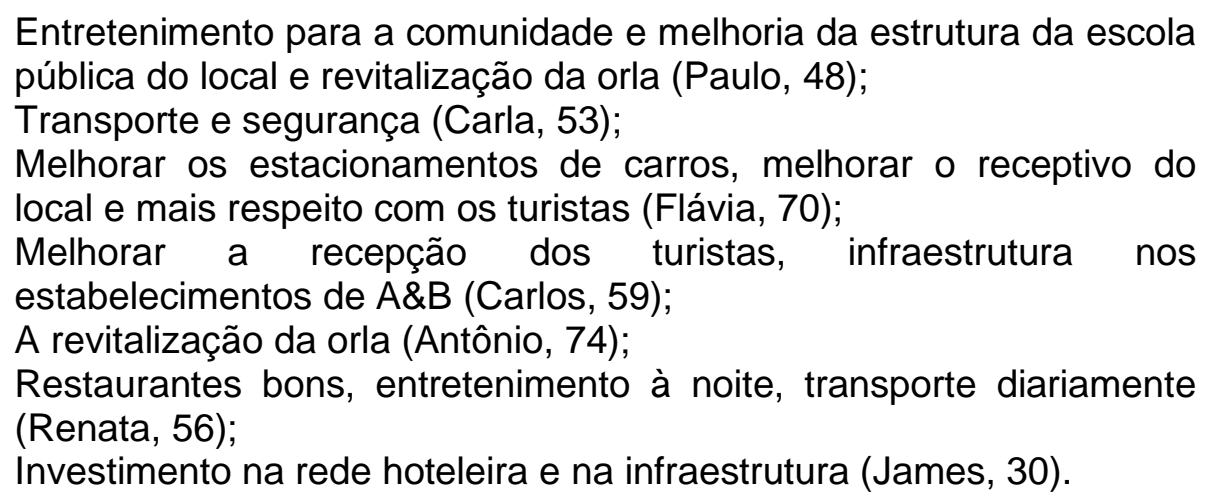

Os depoimentos acima revelam as demandas essenciais e descrevem a importância da infraestrutura local para garantir o bem-estar dos residentes e dos turistas. Implementar ações de melhoria na hospitalidade do destino também tornou-se evidentes, como é enfatizado por Yasoshima e Oliveira (2003):

O planejamento da infraestrutura de recepção e de acolhimento, além de tornar o destino turístico ou cidade de etapa mais amigável para os visitantes, pode também forma uma imagem favorável do lugar, destacando-o num mercado promocional cada vez mais concorrencial (YASOSHIMA; OLIVEIRA, 2003, p.23).

A presença do Poder Público também foi mencionada como benefício para a comunidade e os turistas em 4 (quatro) entrevistas, conforme os relatos destacados: "A presença do poder público na comunidade" (Willian,56);"Atuação do governo do estado e prefeitura" (Gileno, 58); "Investimento do poder público" (Paula, 50).

$\mathrm{Na}$ mesma temática, 14 (quatorze) entrevistados relataram melhorias no marketing turístico, na capacitação das pessoas que trabalham com turismo e trabalhos de conscientizações nos atrativos da localidade. Desse modo, é possível observar a preocupação e o interesse da comunidade no planejamento do turismo como uma estratégia capaz de minimizar os impactos negativos da atividade turística.

Como enfatiza Ribeiro (2009, p.107), "o conceito de desenvolvimento local mais utilizado é o da construção por meio do poder endógeno para que uma localidade legitimada pelos anseios de sua comunidade decida seus objetivos e qual caminho trilhar". Apenas 1 (um) dos entrevistados não soube responder à questão. 


\section{Perspectiva sobre o futuro do turismo em Jenipabu/RN}

Com o intuito de apreender nos residentes as expectativas que eles poderiam ter para o futuro, foi proposto que eles imaginassem as perspectivas para a posterioridade das atividades turísticas em Jenipabu/RN.

Ao analisar os relatos de 13 (treze) entrevistados, percebeu-se certo pessimismo e insegurança quanto ao futuro, conforme os depoimentos a seguir:

Espero que possa progredir e alcançar os objetivos da comunidade (Willian, 56);

Espero que melhorem e que os turistas voltem a frequentar Jenipabu (Mariana, 40);

Tenho esperança que melhore remotamente, posso não estar aqui, mas os jovens podem ser a mudança (Renam, 59).

Por outro lado, no relato de 12 (doze) entrevistados vislumbrou-se uma expectativa de melhora, mas que esta depende de investimentos advindos do Poder Público:

Se houver investimento do poder público vai melhorar, se não houver vai acabar (Paulo, 48);

Se não houver investimento do poder público, a tendência é piorar (Fernando, 58);

Analiso que existem possibilidades de um futuro promissor, se as ações forem implementadas, se não tende ficar no eterno marasmo. (Gileno, 58).

Em 2 (dois) depoimentos observou-se a falta de esperança diante da perspectiva futura do turismo, até pelo fato de estarem cansados de esperar por mudança e nada ser realizado: "Jenipabu só vai ser um ponto de parada para tirar fotos" (Flávia, 70); "Não vai dar em nada, vai voltar o que era antes uma comunidade de pescadores, onde as pessoas eram pobres e felizes" (Marta,34).

Em outros 2 (dois) relatos pôde-se observar a certeza que vai mudar no aspecto positivo de um turismo promissor: "Vai criar um impulso, devido às olimpíadas em torno de 2 a 3 anos vai melhorar." (Isabel, 75); "Com otimismo, espero que melhore" (Gabriel, 30).

\section{A percepção sobre práticas sustentáveis utilizadas pela comunidade}

Em relação às práticas sustentáveis, foram relacionadas questões referentes ao descarte do lixo e do óleo, e se os atrativos naturais, na concepção dos entrevistados, estão sendo tratados de maneira sustentável, respeitando a natureza e o meio ambiente.

No que diz respeito às opiniões que os entrevistados têm em relação ao descarte do lixo, a questão foi dividida em duas categorias: a opinião da comunidade diante do descarte do lixo, e no segundo o conhecimento que os entrevistados possuem a respeito do descarte ideal. As respostas obtidas foram categorizadas no quadro a seguir: 
Quadro 1: Cuidados com o lixo em Jenipabu/RN, 2016.

Frame 1> Waste Care in Jenipabu / RN, 2016.

\begin{tabular}{|c|c|}
\hline Opiniões & $N=28$ \\
\hline 1. Lixo misturado & 14 \\
\hline \multicolumn{2}{|l|}{ "Misturo e levo para a coleta". } \\
\hline \multicolumn{2}{|c|}{ "Misturado por não ter coleta seletiva na cidade". } \\
\hline 2. Separa apenas o lixo orgânico & 10 \\
\hline \multicolumn{2}{|c|}{ "O orgânico é separado para animais que crio". } \\
\hline \multicolumn{2}{|c|}{ "O orgânico é separado para doar para criadores de animais". } \\
\hline \multicolumn{2}{|l|}{ "(galinhas/porcos)..." } \\
\hline 3. Separação de dois tipos de lixo & 02 \\
\hline \multicolumn{2}{|c|}{ "Separo o plástico para reciclagem e o orgânico para animais". } \\
\hline 4. Separação de três tipos de lixo & 01 \\
\hline \multicolumn{2}{|c|}{ "Separo as garrafas pets, alumínio e o orgânico (faço adubo)". } \\
\hline 5. Separa apenas o alumínio & 01 \\
\hline
\end{tabular}

Fonte: DETUR- UFRN, 2016.

Source: DETUR-UFRN, 2016.

O descarte misturado do lixo foi a resposta mais evidenciada: 14 (quatorze) entrevistados relataram que misturam o lixo e em seguida esse é levado para a coleta. No decorrer das entrevistas foi observado que 10 (dez) entrevistados, principalmente os donos de barracas de praia, separam apenas o orgânico para doar aos criadores de animais, como porcos e galinhas. Conforme exposto:

O orgânico é doado para criadores de animais, o restante é misturado e levado para a coleta (Marta, 40);

O orgânico é doado para criadores de animais, o restante é misturado e levado para coleta (Gabriel, 30);

O orgânico é separo para criadores de animais, e o restante e misturado e levado para a coleta (Flávia, 70).

No decorrer da análise, a questão foi dividida em categorias para destacar a relevância das respostas. Com as respostas mais relevantes, as categorias seguintes mencionam até três tipos de lixo que são separados, em que 3 (três) entrevistados relataram:

Separo o plástico para a reciclagem e o orgânico para os animais, o restante coloco no lixo e levo para a coleta. (Liana, 36);

$O$ vidro e o orgânico separo reaproveitando o lixo para transforma em adubo (Neuza, 68);

Separo as garrafas pets e os alumínios para a reciclagem e reutilizo o orgânico para adubo (Isabel, 75).

Nos depoimentos a seguir, será ressaltado o conhecimento dos entrevistados acerca do descarte ideal do lixo. Nesse contexto, diante da quase integralidade dos 
relatos, 27 (vinte e sete) entrevistados têm conhecimento da maneira de descarte ideal, muito embora ainda não destinem o lixo separado para coleta. conhecimento e importância da coleta seletiva são visíveis:

O ideal seria a coleta seletiva, uma estrutura fundamental do poder público (Gileno, 58);

O ideal seria a coleta seletiva pelos órgãos públicos, a conscientização (Nilda, 48);

É misturado e levado para a coleta. O ideal seria a coleta seletiva organizada pela prefeitura (Rian, 34);

A prefeitura deveria investir em coleta seletiva (Luciene, 40 );

O ideal seria a coleta seletiva mantida pela prefeitura (Renata, 56).

A quase totalidade dos entrevistados relatou que a coleta seletiva é de responsabilidade de órgãos públicos, apenas 1 (uma) pessoa disse que não tinha conhecimento do descarte ideal.

\section{Descarte real do óleo impróprio para o consumo}

O óleo é outro fator importante, caso seja destinado para o descarte ideal, complementa a sustentabilidade local. Nos depoimentos a seguir são apresentadas as opiniões que os entrevistados têm em relação ao descarte do óleo que utilizam. Verificou-se que 19 (dezenove) entrevistados jogam o óleo no ralo ou no quintal, lugar onde é armazenado, mas a destinação é o lixo. Como é possível observar:

Jogo no ralo da pia (Mariana, 40);

Jogo fora no quintal de casa (Giane, 27);

Praticamente não utilizo óleo, mas quando fica velho jogo no ralo (Marta, 68);

Coloco no recipiente e depois jogo no lixo, não jogo no ralo para não afeta o solo (Erika, 23).

Em poucos casos, 8 (oito) entrevistados relataram que doam o óleo para instituições de caridade ou para pessoas conhecidas que o reaproveita na fabricação de sabão. Sendo esses conscientes das utilidades do óleo ao ficar impróprio para o consumo, destinando-o corretamente: "O óleo é armazenado é doado a uma instituição de caridade" (Luciene, 36); "Armazeno e levo para uma conhecida fazer sabão" (Flávia, 70); "Armazeno para doar para uma instituição de caridade" (Luciene, 40). Apenas um entrevistado relatou "Não uso óleo por motivos de saúde" (Izabel, 75).

\section{Descarte ideal do óleo impróprio para consumo segundo a comunidade.}

As alternativas tradicionais do descarte do óleo são: o lixo ou o ralo da pia. Muitas vezes têm-se o conhecimento de que é errado, mas a opção de banco de coleta é escassa na maioria dos destinos turísticos. $\mathrm{Na}$ análise do descarte ideal do óleo, foi observado que 15 (quinze) entrevistados possuem conhecimento a respeito da destinação ideal do óleo e responsabilizam os órgãos governamentais que não 
investem em postos de coleta de óleo impróprio para o consumo. Conforme os relatos a seguir:

Deveria ter posto de coleta para entregar o óleo velho (Mariana, 40); A prefeitura deveria incentivar e ajuda na coleta do óleo. (Marta, 34); $O$ ideal seria doar para reaproveitar, o que dificulta por não ter um banco de coleta (Giane, 27);

O descarte ideal seria para doar para pessoas que fazem sabão (Renata, 56).

Por outro lado, 5 (cinco) entrevistados não têm conhecimento do descarte ideal, como se pode observar nos relatos: "Não tenho conhecimento de como seria o descarte ideal" (Renam, 40); "Não sei qual seria o descarte ideal” (Paula, 50).

\section{Cuidado sustentável dos atrativos naturais de Jenipabu/RN}

Este tópico apresenta as opiniões dos entrevistados diante do cuidado sustentável em relação aos atrativos naturais. Assim, de acordo com os relatos obtidos, pôde-se observar que a maioria foi de total concordância.

É sabido que estão incorporados numa Área de Proteção Ambiental, no entanto, a maioria relata que eles não são tratados de maneira sustentável. Ao analisar as opiniões, 14 (quatorze) entrevistados acreditam que os atrativos naturais não estão sendo tratados de maneira sustentável. De outro modo, 8 (oito) pessoas disseram apenas não, e outras complementaram com questões a respeito do desmatamento e devastação:

\footnotetext{
Não, há muito desmatamento, eles proibiram o uso turístico da lagoa, mais próximo da mesma a o desmatamento para a construção de casas (Rian, 34);

Não devido a devastação. (Isabel, 75);

Não, as pessoas estão acabando com as dunas (Flávia, 70);

Não, há um grande desmatamento (Neuza, 49).
}

Assim, 9 (nove) entrevistados acreditam que estão vivendo de maneira sustentável. E 5 (cinco) disseram apenas que sim, outros completaram que devido a APA há um cuidado maior nos atrativos:

Sim devido a APA com a fiscalização se não tivesse já tinham acabado com os atrativos (Marta, 34);

Sim devido a APA (Renam, 30);

Sim, devido a APA, que é responsável pela preservação dos atrativos naturais (Luciene,40).

Em relação às opiniões contrárias, 5 (cinco) entrevistados, não concordaram com o tratamento correto, mesmo quando foi enfatizado a APA no relato. Em razão de ainda ocorrer desmatamento em área não permitida e o uso abusivo dos atrativos. Os atrativos naturais deveriam ser preservados/conservados por estarem dentro de uma Unidade de Conservação: 
Não totalmente, pois tem muito desmatamento e lixos nas ruas (Carla, 68);

Não totalmente, há muita devastação principalmente os manguezais que estão poluídos (Gabriel, 59);

Só a lagoa devido a APA (Giane, 27);

Na APA a fiscalização é regular, no entanto a limpeza deixa a deseja nos atrativos (Willian, 56).

Pode-se observar, que a falta de fiscalização e cuidados do órgão IDEMA e do Governo ainda é escasso. Tal fato põe em risco o ambiente inserido dentro da área de proteção ambiental, que comporta os atrativos naturais e materiais, representando o destino turístico de Jenipabu.

\section{Considerações finais}

A partir da análise da literatura, percebe-se que o planejamento do turismo contribui com a valorização dos destinos, a permanência de turistas e o bem-estar dos residentes. Desse modo é essencial a participação da comunidade nas decisões que tratam sobre a atividade turística.

Em relação à análise da prática turística local, pode-se afirmar que a atividade de Jenipabu se encontra desvalorizada e em decadência, conforme enfatizaram os relatos. É válido dizer que os atrativos da localidade são capazes de modificar a situação do destino devido à singularidade deles. O passeio de jangada (sem motor), passeio de charrete e a festa da argolinha complementam os atrativos na comunidade.

O planejamento sustentável do turismo na comunidade é preocupante, visto que pequenas práticas do cotidiano no cuidado com os resíduos sólidos (descarte do óleo de cozinha e a coleta seletiva) não ocorrem adequadamente entre os comerciantes.

Pôde-se também observar que a prefeitura não disponibiliza banco de coleta do óleo e lixeiras seletivas. A falta de interesse do Poder Público no investimento de coleta seletiva na comunidade é evidente. Todavia, a colaboração e participação dos residentes são essenciais para o planejamento do turismo sustentável.

Diante do cuidado sustentável dos atrativos naturais, é evidente que a APA contribuiu para minimizar os impactos negativos causados ao meio ambiente. No entanto, a fiscalização do IDEMA ainda é precária, pois há relato de contínuo desmatamento e sujidades nos atrativos naturais. Conclui-se que são necessários estudos sobre identidade da cultura local, as condições de fiscalização da APA e a gestão da qualidade nos serviços de hospitalidade.

\section{Referências}

AMORIM, C. G. Oportunidades de Negócios Geradas pelo Ecoturismo em Unidades de Conservação. In: GIMENES, M.H.S.G. Oportunidades e Investimento no Turismo. São Paulo: ROCA, 2003. 
BAUER, M.W.; AARTS, B. A construção do corpus: Um princípio para a coleta de dados qualitativos. In: BAUER, Martin W.; GASKELL, George. Pesquisa qualitativa com texto, imagem e som. Um manual prático. Petrópolis: Editora Vozes, 2004.

BENI, C.M. Política e estratégia do desenvolvimento regional - Planejamento integrado e sustentável do turismo. In: LAGE, B.H.G.; MILONE, P.C. Turismo: Teoria e Prática. São Paulo: Atlas, 2000, p. 165-171.

BENI, M.C. Turismo: Planejamento e Capacidade de Gestão. São Paulo: Editora Manole Ltda, 2012.

BOULLÓN, R. Ecoturismo. Sistemas naturales urbanos. B. Aires: Turísticas, 2003.

BRUNDTLAND, G. H. Nosso futuro comum. Rio de Janeiro: FGV, 1987.

BRUNELLI, L. H. O imaginário e as oportunidades do turismo pós-moderno. In: GIMENES-MINASSE, M.H.S.G. Oportunidades e Investimento no Turismo. São Paulo: ROCA, 2003.

COOPER, C. Turismo e Praticas. Porto Alegre: Bookman, 2007.

DESLANDES, S.F. Teoria Métodos e Criatividade. Petrópolis/RJ: Vozes, 2016.

DIAS, R. Introdução ao Turismo. São Paulo: Atlas, 2008.

IGNARRA, L.R. Fundamentos do Turismo. Rio de Janeiro: Editora Senac, 2013.

MACHADO, A. Ecoturismo: um produto infalível: a experiência do Rio Grande do Sul. Rio de Janeiro: Editora Senac, 2005.

MAGALHÃES, C.F. Diretrizes para o Turismo Sustentável em Municípios. São Paulo: ROCA, 2002.

MEKSENAS, P. Pesquisa Social e Ação Pedagógica: conceitos, métodos e práticas. São Paulo: Edições Loyola, 2002.

MENDONÇA, R.; NEIMAN, Z. Ecoturismo no Brasil. Barueri: Manole, 2005.

MIELKE, E.J.C. Desenvolvimento Turístico de Base Comunitaria. Campinas/SP: Editora Alínea, 2009.

PHILIPPI, A.J.; RUSCHMANN, D.V.D.M. Gestão Ambiental e Sustentabilidade. Barueri/ SP: Manole, 2010.

PRAIAS DE NATAL. Fotografia Passeio de Dromedário: Diversão das Arábias em Natal/RN. Natal: Guia Turístico do Rio Grande do Norte, 2019.

RIBEIRO, M. Turismo Comunitário: Relações Entre Ator e Convidado. In: PANOSSO NETTO, A.; ANSARAH, M.G.R. Segmentação do Mercado Turístico. Barueri/SP: Manole, 2009.

RUSCHMANN, D. A experiência do turismo ecológico no Brasil: um novo nicho de mercado ou um esforço para atingir a sustentabilidade. Turismo: Visão e Ação, Balneário Camburiú/SC, v. 2, n. 5, p.81-90, mar. 2000.

RUSCHMANN, D. Turismo e planejamento sustentável: a proteção do meio ambiente. Campinas: Papirus Editora, 2016.

SANTOS, C. Fotografia da tradicional festa de argolinha da praia de Jenipabu, em Extremoz. Extremoz: Canindé Santos Fotografias e Reportagens, 2019.

SOARES, C. Cidades Jenipabu. Fotografia da Lagoa de Jenipabu. São Paulo: Grupo Abril, 2012.

SECOM/IDEMA (Rio Grande do Norte). Área de Proteção Ambiental Jenipabu APAJ. 2017.

Disponível

em: 
$<$ http://www.idema.rn.gov.br/Conteudo.asp?TRAN=ITEM\&TARG=943\&ACT=null\&PA $\mathrm{GE}=0$ \&PARM=null\&LBL=Unidades+de+Conserva\%C3\%A7\%C3\%A3o $>$. Acesso em: 25 maio 2018.

TOMAZZONI, E.L. Turismo e Desenvolvimiento Regional. Caxias do Sul/RS: EDUCS, 2009.

YASOSHIMA, J.R.; OLIVEIRA, N.S. Gestão da Qualidade na Recepção e no Acolhimento dos Turistas In: GIMENES, M.H.S.G. (Org). Oportunidades e Investimento no Turismo. São Paulo: ROCA, 2003, p. 22 - 29.

Margareth Ribeiro Guedes: Universidade Federal do Rio Grande do Norte, Natal, RN, Brasil.

E-mail: margarete_hsm@hotmail.com

Silvânia Melo da Cunha: Universidade Federal do Rio Grande do Norte, Natal, RN, Brasil.

E-mail: silvaniamelo0508@gmail.com

Link para o currículo Lattes: http://lattes.cnpq.br/9958317186143829

Camila Kayssa Targino Dutra: Universidade do Estado do Rio Grande do Norte, Mossoró, RN, Brasil.

E-mail: camila_targino2010@hotmail.com

Link para o currículo Lattes: http://lattes.cnpq.br/9872037081151736

Amanda Almeida Gomes Dantas: Universidade Federal do Rio Grande do Norte , Natal, RN, Brasil.

E-mail: almmeidaamanda@gmail.com

Link para o currículo Lattes: http://lattes.cnpq.br/9326381942620579

Sueli Aparecida Moreira: Universidade Federal do Rio Grande do Norte, Natal, RN, Brasil.

E-mail: suelimoreira@yahoo.com.br

Link para o currículo Lattes: http://lattes.cnpq.br/9469781068838287

Data de submissão: 14 de fevereiro de 2020.

Data de recebimento de correções: 07 de abril de 2020

Data do aceite: 07 de abril de 2020

Avaliado anonimamente 